\title{
Marketing challenges in the software component business
}

\author{
Pauliina K. Ulkuniemi \\ University of Oulu, Faculty of Economics and Business Administration, Department of Marketing, \\ P.O.Box 4600, 90014 Oulun yliopisto \\ Finland \\ Pauliina.Ulkuniemi@Oulu.fi
}

\section{Nina M. Helander}

Tampere University of Technology, Institute of Business Information Management

\begin{abstract}
This paper discusses marketing challenges in the special context of software component business. Commercial software components have received a lot of attention in current research on software engineering and software business. Technical aspects of developing and using this kind of software have been discussed rather extensively in the literature. In addition to these, also the management related aspects have received a growing attention. However, these management studies have so far mainly been concentrated on the buyer's point of view, leaving the supplier perspective and the question how to market and sell the developed software components out of foci of the current literature, yet the marketing issues represent big challenges for these companies.

The idea of software component business is to have competitive markets where software components can be sold and bought as standard components and exchanges can be conducted without much joint development work between the software seller and buyer. However, this kind of ideal for single exchanges in an industry where close co-operation has traditionally been needed in exchanges creates many marketing challenges especially in terms of customer interface. Thus, in this specific context, we are dealing with very interesting marketing questions.

The purpose of this research is to contribute to our knowledge on marketing management issues related to commercial software component business from the software component supplier point of view. This empirically driven paper aims at increasing our knowledge about the challenges related to commercial software component business and proposes answers how to overcome these challenges. As the pre-existing literature about marketing commercial software components is still rather nonexisting, the present study is methodologically emphasizing inductive research methods as it aims at local theory development through an empirical analysis.
\end{abstract}

Keywords: marketing challenges, marketing competencies, software component 


\section{Introduction}

International computer software industry has emerged as a recognised global activity during the eighties and nineties. In addition to pure software products and solutions, many automation, electronics and telecommunication systems include tailored software that is invisible to end-users, but plays still a central role. Instead of using tailored software solutions produced in close co-operation with suppliers and sub-contractors in various software projects, commercial software component have become an increasingly interesting choice in the development of these systems, too, due to standard interfaces and open technologies. Thus it is not a surprise that commercial software components have received a lot of attention in current research on software engineering and software business.

In the current literature, technical aspects of developing and using this kind of software have been discussed rather extensively. Covered aspects include, e.g. architectural issues in component based software development, quality assurance, and component specification issues. In addition to these, also the management related aspects have received attention. Underlying this interest has been the fact that the industry experiences in relation to commercial software component business have brought out many kinds of managerial challenges. Especially the buyer's or component integrator's perspective has received a lot of attention in terms of developing component acquisition and integration guidelines (e.g. Liu \& Gorton 2003; Meyers \& Obendorf 2001). However, the marketing perspective, i.e. the perspective of selling the components, has not gained that much of attention in the literature. The software supplier's perspective has so far only attained technical interest in terms of developing the components, but the managerial interest on how to market and sell the developed software components has not yet been in foci of the current literature.

The software component business can be characterized as striving towards high level of standardization of software interfaces and single exchanges. In other words, the aim is to create a software component market where software components can be sold and bought as standard components. Furthermore, the exchanges can be conducted without much joint development work between the software seller and buyer, which is typical for more traditional exchanges in $b$-to-b software exchanges, e.g. sub-contracting. However, this kind of ideal for single exchanges in an industry where close co-operation has been needed in exchanges creates many marketing challenges especially in terms of customer interface. In the so-called transactional relationships buyers and sellers are seen as interacting only with rather selfish consideration, aiming at merely finalising the single transaction at hand. Future co-operation is not actively considered in the transaction, and the seller is usually valued according to its current products and prices. The view of markets involved in this kind of business transactions is more or less related to the classic economic theory of perfect markets where there exists several sellers and buyers possessing a complete knowledge on the products and where the price is determined by faceless market forces.

In all, the software component business represents a new and emerging market where the nature of the relationship between the seller and buyer has not found any typical form. On the one hand there is the ambition towards single exchanges where as on the other hand the context demands a more close relationship between the counterparts. Thus, in this specific context, we are dealing with very interesting marketing questions, such as what are the challenges faced by software component suppliers and what kinds of marketing competencies they need to overcome these challenges.

The purpose of the present research is to contribute to our knowledge on management issues related to commercial software component business from the software component supplier point of view. The paper represents an empirically inspired study, as the phenomenon under study is defined from a specific empirical context, i.e. from the software component business. The paper aims to increase our understanding of what are the marketing challenges related to commercial software component business and proposes answers how to overcome these challenges. Firstly, we will identify the marketing challenges faced by component suppliers that are able to be derived from the literature dealing software business in more general terms. Secondly, we will conduct a qualitative empirical study including a multiple case study setting. Through the findings from the empirical study we will develop local theory focused on the marketing competencies of component suppliers that takes into account the specific features of software component business. The paper also puts forward managerial contributions. As the pre-existing literature about marketing commercial software components is still rather non-existing, the present study is methodologically emphasizing inductive research methods as it aims at local theory development through an empirical analysis. 


\section{An overview to software component markets from the supplier point of view}

A software component is usually understood as a reusable and independent computer program that is accessible through specified interfaces (see, e.g., Meyers \& Oberndorf 2001, Brereton \& Budgen 2000, Sprott 2000, Szyperski 1998). The size of the software components may vary a lot, e.g. software components can be even as large entities as an operating system or a data-base which are included in a larger software system. In the present study, we define commercial software component as any reusable computer program that is integrated into a larger software-based system solution as an individual operational part, and that is not valued by the end customer as a standalone application. Thus, from the component supplier point of view, the software component is sold further through a system integrator company to the end customer as a part of a larger software system.

In our definition of a commercial software component, we include both the commercial off-the-shelf (COTS) software and modified off-the-shelf (MOTS) software. A COTS software is sold, leased or licensed to the general public in multiple, identical copies (Meyers \& Obendorf 2001), whereas MOTS software is offered by the supplier with services for tailoring the software to acquirer-specific requirements (Meyers \& Oberndorf 2001, IEEE 1998). Additionally, open-source components can be regarded as forming their own unique group of software (see, e.g., Meyers \& Oberndorf 2001), as they are components whose specification is open, fully defined, available to the public, and maintained according to group consensus. However, we have left out from the scope of this study the open source software components, as the marketing challenges of open source software is rather different than in the case of commercial software components.

The software component markets are still rather undeveloped and scarce. From the customer's perspective, the lack of available components and on the other the lack of industry standards illustrate the current software component markets (see e.g. in Ulkuniemi 2003). Standards are being developed, but as the whole field is rapidly developing and very complex in nature, standards may be rather difficult to create and take a long time. However, there still seems to be an evident trend towards increasing use of commercial software components in the software development. One important issue in the development of the market is obviously the standardization. Allen (2001) has discussed some of the most important standardization efforts in the software component community. $\mathrm{He}$ aptly points out that for buyers, there are many difficulties related to the standards development. Standards often change over time, merge with each other and even fall into disuse. This brings forth many problems for the buyers, as well as for the sellers. One reason for difficulties in the use of standards is the fact that there are several standardization organizations in the software component markets and several different, partly even overlapping standardization efforts are being made. Also, as the software technologies are developing at such a high speed, some areas are left with scant attention as far as standardization efforts are concerned. On the other hand, component sellers are trying to develop additional features exceeding the standard features in order to gain competitive advantage. Also, some vendors try to gain control over the markets by acting strongly in standards development. (Allen 2001.)

According to Allen (2001), the idea of software component markets is not entirely new. Ever since 1968 various efforts have been made in order to create marketplaces for standard software. The underlying assumption has been that as component markets have been developed in other, more traditional industries, the same could be done in relation to software. However, large-scale software component markets have only recently been getting started. Estimates for software component market growth in terms of monetary measures of sales have suggested a considerable expansion of the market. During the collection of the empirical material for this study in 2000 and 2001 it was estimated, by market researchers such as Gartner, Giga, Ovum, and PriceWaterhouseCoopers, that the market size for software components would grow from approximately 1,5 billion dollars to approximately 3 billion dollars between 2000 and 2001 (Bass, Clements and Katzman 2001). In addition to the growing volume of the software component market in terms of market forecasts, also number of software component supplier companies has become successful (Bass, Clements and Katzman 2001).

There are various different kinds of sellers of software components. As the definition of component itself is difficult, the notion of component suppliers also becomes diverse. On the basis of industry literature, some of the suppliers offer COTS components in the strictest sense of the term, while some of the suppliers are also providing services that could be regarded more as customized software, i.e. MOTS components, than COTS components. In fact, COTS components refer more to product 
business logic, whereas MOTS component business is more or less service oriented business, as MOTS components include tailoring services offered to the customer. Many of the sellers, however, aim at increasing COTS software component selling. Harmon (1999) divides the supplier companies operating in the component markets into three types: companies selling products that include components, companies selling components that they develop themselves and companies selling components developed by others. In our research, the focus is on studying such supplier companies that are selling components that they develop themselves. In fact, the first type of component sellers, the companies selling products that include components, represents the potential customer organizations for such component suppliers that we are interested in this study. These potential customers can also be named as system integrators (SI).

\section{Review of the marketing challenges in the software component business}

From a software component supplier point of view, two major marketing challenges are able to be derived from the pre-existing literature. First of all, there is the challenge to have large enough customer base, i.e. markets, for the developed component. As the costs for productization of software are high, there needs to be enough sales volume to cover the development and productization costs of the software component. These marketing challenges are named in the following as the "market creation challenges". The other major marketing challenge for a software component supplier is to deal between the product and service marketing logic: software component business is in its nature product marketing, but on the other hand practical experiences have shown, that the problems that should be solved before the real growth of software component business need relationship marketing and customer relationship management skills that are more characteristic for service oriented project marketing (see, e.g. Helander, Ulkuniemi \& Seppänen 2002). This kind of product vs. project business marketing dilemma is discussed in the following under the topic "relational challenges".

\section{Market creation challenges}

The software component suppliers face marketing challenges that are related to market level issues. The commercial software component markets have been described as yet only emerging and very immature. An efficiently functioning software component market with products suitable for a certain industry would be needed to overcome the major problems associated to buying and using software components. A more efficient market would be characterized by a broader set of suppliers with established business models, interfaces determined by industry standards, commonly agreed business practices and controllable co-operation between contracting parties, among other things. Although the development of more efficient markets has been argued to be relevant especially from the buying companies' perspective (e.g. Ulkuniemi \& Seppänen 2004), this is equally, if not even more essential from the component supplier's perspective. Thus, it is not enough for the component supplier to manage the challenges related to managing customer relationships one by one, but they also need to pay attention to developing the whole market.

The role of standards in component market is evident. The purpose of software standards is to ensure that components provided by different sellers can inter-operate (Messerschmitt \& Szyperski 2000). Thus, it is easy to understand why the COTS business is described as a standards-based marketplace; markets are based on products using the same defined standards (Meyers \& Oberndorf 2001). In the COTS software component community, there are particular standards bodies, i.e. groups including representatives of both component sellers and buyers. The idea of these standards is that the software component seller develops the kind of products that are based on these standards, while customers adopt these standards as part of their own system specifications.

\section{Relational challenges}

As already mentioned, there are differences in the marketing logics of a software product company compared to a software project company. Referring to the work of Alajoutsijärvi, Mannermaa and Tikkanen (1999), differences can be identified at least in central capabilities, object of exchange, production, customer base, nature of markets, branding, nature of exchange, and type of organisation. These differences in the marketing logics cause challenges especially in relational terms, as the nature of the customer relationships and the way they are managed varies rather lot between software product and project businesses. Companies that aim to become software component suppliers, need 
to find a right balance between the product and project business logics in terms of how the customer relationship is managed.

In software project business, the central capabilities of the supplier company are related to project marketing and management, as the object of exchange is a unique project designed to a one customer. As the customer base is rather narrow and the customers are well-known, the nature of exchange between the counterparts is interactive, mutual and usually long-term oriented. Branding is not so important, as the markets are usually familiar, rather local and closed. On the contrary, the central capabilities of a supplier company in software product business are related to productization, branding and marketing channel management. The customer base is broad and faceless, as the nature of markets is more distant, international and competitive. The nature of exchange between the counterparts is more short-term oriented than in the software project business and the nature of exchange is in overall more simple, opportunistic and product-oriented. (Alajoutsijärvi, Mannermaa and Tikkanen 1999) Thus, the software project business is far more relationship and service oriented business than the software product business is.

It can also be concluded that it is more typical for the software project business to be near of the customer and to nourish the relationship with the customer. In fact, software project companies market their competencies (see e.g. Gibbert, Golfetto and Zerbini 2005) to their customers; their market offering is to solve the problems that customers have in their own business processes. Thus, in the software project business it is natural, and even necessary, that suppliers are such a close to the customer that it is possible to understand the way the customer creates value in its business operations. In other words, the idea is to understand customer's value creation process.

The purpose of the examination and determination of the customer's value creation process is to better understand the concerns related to the customer's business activities (see e.g. Hirvonen \& Helander 2001). Another advantage of understanding the customer's value creation process is that the supplier can more easily communicate with the customer concerning the value that it can create for the customer (Anderson \& Narus 1998). As MacStravic (1999) has pointed out, it is important to communicate with the customer in the 'right' way so that the customer can recognise the value that the supplier is able to create. Thus, the supplier is able to more efficiently to market its competencies to the customer.

In the special context of software component business, the value creation processes of both the software component supplier and its customer can be divided in few main phases that help to better grasp the idea of value creation process. Based on the analysis of Hirvonen \& Helander (2001) and Helander (2004), at least following phases of the value creation process from the viewpoint of the supplier supporting its customers' value creation processes can be identified: marketing, sales, delivery, after-sales and maintenance. Also the phases of R\&D and production, are important phases in the overall value creation process of the supplier. The parallel phases from the viewpoint of the customer are need identification, acquisition, integration, and utilisation/further sales phases. From the supplier point of view, these customer's phases should be understood and aimed to be supported in order to create value for the customer. In all, this is a question of customer-linking capabilities, as discussed by Day (1994).

Although the concerns that customers have in the different phases of the value creation process are more easy to identify and understand in software project business, in which the supplier is already rather close to the customer, we argue that also software product companies can benefit from understanding the logic of customer's value creation process. Through the empirical study we are going to examine which kind of marketing logic, product or service oriented logic, the case companies are following currently. Additionally, we will highlight in what way the different marketing logics are related to the presented phases of customer's value creation process. Through the analysis we are able to present what kind of marketing logic would be most successful one for the component suppliers and to what extend the different kinds of suppliers can benefit from the value creation process approach.

\section{Empirical study}

The purpose of the empirical part of the study is to add to our understanding of the marketing challenges faced by software component suppliers. The methodology used follows the abductive 
research logic, where both theoretical propositions are used but also the empirical material is used as a source of knowledge in further developing the model. However, the study is more at the inductive than deductive. The study represents a qualitative methodology and includes a multiple case study setting. In selecting the cases, we have used the criteria driven from the existing knowledge on alternative types of software component suppliers. This means that we wanted to study both suppliers operating in a more product based logic as well as suppliers operating closer to the project based logic. Therefore, we have selected four suppliers to study, see Figure 1.

\section{COM PONENTSUPPLIER B U S IN ES S LO G IC}

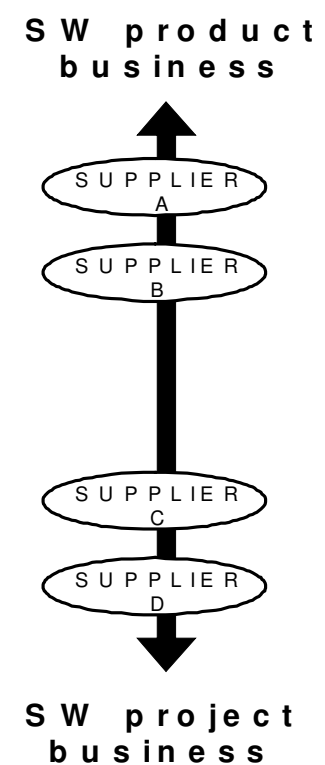

Fig. 1. The range of component suppliers

However, as it is evident that it is not enough to merely the suppliers if we wish to understand the marketing challenges. We also need to take a look at the customer's perspective. Therefore, we have added also the customers into the analysis. In order to keep the case study setting manageable, we have chosen a setting including altogether four suppliers ${ }^{1}$ : Ada Technologies (Supplier A in Figure 1), Bolona Data (Supplier B), Cersa Automation (Supplier C) and Dinera Technology (Supplier D). Also, two customers were studied: Xiamo, which is a customer of Ada Technologies and Bolona Data and Yosigemo, which is a customer of Cersa Automation and Dinera Technology. Thus we have reduced the number of customers in the case study setting. The empirical material is composed of interviews of the representatives of the analyzed suppliers and their selected customers.

\section{Customers}

The Xiamo is a part of a large company in the electronics industry. It operates in business-to-business markets and manufactures telecommunication equipment products which include both hardware and software. Software is an essential part of the company's products; part of the core competence of the company is its expertise in certain kinds of software technologies. The company has long history in software engineering and it has developed comprehensive processes for software development and testing. It has produced most of the software by itself, although several software subcontractors have been used as well. The company has a number of software subcontracting and partnering relationships, through which it has been able to acquire the tailored software solutions flexibly. The company had recently also started using standard commercial solutions, i.e. software components.

\footnotetext{
${ }^{1}$ Names of the companies have been changed
} 
Despite the well-defined component-based software engineering processes and practices in managing subcontracting and partnering relationships with software suppliers, the company felt it lacked advice for purchasing commercial software components, as well as guidelines for the reuse and maintenance of such components. Moreover, the roles of the company's general purchasing organisation and its software development department were unclear with respect to buying the commercial software components to be integrated into the company's own products. The former possesses considerable expertise in contracting and buying, but only the latter has the necessary technical skills to identify and choose potential components and suppliers, as well as to collaborate with the suppliers in ongoing product development projects.

The customer company had difficulties in identifying the needs early enough in the software engineering process, and this made the software component needs emerge in rather short time period and the purchases needed to be made quickly. Also, as the component needs were not taken into account early in the engineering process of the software system, components with suitable interfaces were difficult to find. All in all, the customer company regarded the software component markets yet very immature; suitable suppliers and components were scarce and the whole industry lacked standard operating procedures.

Our second analysed customer, Yosigemo, can be labelled a high-tech company that operates in the electronics-manufacturing-equipment industry. The company operates in business-to-business markets, providing its organisational customers larger automated production systems based on integration of computing into electromechanical components and products; i.e., the company is a typical example of a system integrator (SI) operating in the field of embedded software business. The software system the company developed enables flexible production processes by making it possible to create and modify production orders, and it allows simultaneous control of production orders without stopping production. This brings flexibility to the customer's production, by providing the chance to use a single production line for both mass and custom production.

The company designs all the software that is needed in the system solution, but most of the actual software development and implementation work has been acquired from the suppliers Cersa Automation and Dinera Technology. These suppliers have earlier been operating mainly as subcontractors, by charging $\mathrm{Y}$ at an hourly rate, but recently there has been a strong shift toward acquiring the needed software from the suppliers more as components than on a resource-based subcontracting basis. Besides these two main suppliers of software, Yosigemo has a few other software suppliers and a greater number of suppliers of hardware.

It can be stated that the company has somewhat scarce software development resources. Thus, it is rather dependent on the competencies of its software suppliers. In fact, the suppliers $C$ and $D$ have very strong presence in all of the value creation process phases of the company. Firstly, they help to identify the needs of the company as they participate in the R\&D software operations of the system solution. Secondly, they have very close relationship with the Yosigemo. The mode of close relationship has its roots in the history of subcontracting type of exchanges. The close relationship and strong interaction between the customer and its suppliers have an influence on the acquisition phase, leading towards more of partnership type of exchanges than pure market transactions. Thirdly, the suppliers' role in the integration of the software components in the system solution is very strong. The suppliers are even participating in the last phases of the system solution integration - the phase where the system is integrated in the other systems of the end customer. Fourthly, the suppliers have had rather extensive responsibilities in maintaining the system solution, even after when the system is up and running in the end customer's premises. However, the end customer has not been satisfied to this kind of way of action, where not only the system integrator but also the suppliers of the system integrator have been visible to the end customer, leading to a situation where the end customer has been forced to have interaction and time-consuming contacts with several actors.

From the market creation challenges point of view, Yosigemo has put much of effort to enhance standardization development in the industry. $Y$ has strong presence in standardisation comities, as it would like to see the industry to develop towards standard interfaces that would further enhance the growth of true component markets. Additionally, standard interfaces would decrease the needed amount of integration work, which has been for the $Y$ the most exhausting phase of developing and implementing the system solution up and running in the end customer's premises. 


\section{Component suppliers}

Ada Technologies represents a company strongly focusing on selling software as commercial components. The company has two business units; one focusing on developing and selling the actual software components and another focusing on selling consultation services supporting the use of these components. These two units are highly separated and operating very independently. Since it's foundation in the beginning of the 1990's, the company has strived towards operating on a product business logic; i.e. focusing on selling standard software.

The internet is the main distribution channel; the software can be freely evaluated through internet and potential customers can then contact the seller in order to decide which kind of license would suit them best. The pricing follows pre-determined list prices, with different types of licenses for different purposes. Also the technical support for the customer is handled through a web-service. Thus, the customer interface is organized as standard and light as possible. The main areas of marketing activities to be developed include being more active in fairs and industry exhibitions. Customer needs are detected through gathering information from the personnel involved in the customer interface that is mainly the technical experts. Future roadmaps for the development of the component are only scantly communicated to the customers in advance.

Bolona Data is a company focusing on selling mainly one product, which has been first developed when the company operated in project business. Afterwards, the company was divided into two business units; one focusing on services, i.e. project business and the other on product business. The product side also has a separate support services unit, which provides support for the customers using the software component. The component supplier has developed standard order and delivery processes and thus tries to minimise the needed managerial effort in the customer interface. All in all, the company has rather complex and long-term relationships with many of its' customers, many of them dating back to time when the company operated on project business logic. However, as the company has nowadays adopted the product business logic, the company has problems in conducting exchanges in this new way. The company's product management actively gathers customer information both formally and informally in order to develop the components further. Key customers have more power regarding the future versions of the component.

Cersa Automation represents the middle position in our continuum of software product vs. project business. The company has its root in the project business, but already for couple of years it has had also an own unit concentrated on product business. The company operates at global level and it has customers from several different industries. However, telecommunications sector can be seen as representing the main customer segment. The company possesses different kinds of customer interfaces and processes for the product business, but in project business the customer relationships are usually very close and long-term and they include e.g. working in the customers' premises. On the other hand, the product/component business unit has more mass-market oriented approach, thus the marketing efforts are more concentrated on such issues as branding and development of distribution channels. In project business, sales people and project managers gather information directly from the customers when they interact in close co-operation. In product/component business, the applied approach is more of product-oriented: the company has started to develop products more from their own initiative than by scanning customer needs.

As the Cersa Automation has its roots in the project business, the move towards product business has not been easy, even though the product business has been organized as an own rather independent unit. The company has faced problems especially in building adequate delivery channels for the software products and components, as well as creating a customer lock-in for the product business. For a project business the customer lock-in develops rather naturally from the close co-operation between the supplier and the customer, but in the product business the logic for customer lock-in is not so straight forward, especially if the offered product or component is highly standardized and general in its nature.

Dinera Technology is a project business oriented company that operates mainly at national level. As typical for a project business oriented company, its sales force is organized according to biggest customers and tailoring plays remarkable role in the customer deliveries. The company would like to participate more on the customer's software design and requirement management processes, but currently they are somewhat forced to answer to needs that customer articulate after their internal 
requirement setting and software design. The company's main emphasis is still on developing software to customers as project-based pricing, not as real software components. However, they already have had a few shared component development projects from Y's initiative with Y's other suppliers.

In all, the Dinera Technology has not even been very eager to move towards componentization and product business. Instead, they would like to have even more co-operation with their customers in the form of deeper participation of the customers' value creation processes. However, at least the Yosigemo is moving to another direction in supplying software; they would like to get most of the needed software as components instead of subcontracting mode in the near future. This may decrease the possibilities to do future co-operation with Dinera Technology. Even if $D$ would like to move towards more product oriented business they would still have rather concrete pitfalls to overcome before they could enter to real product business as they have given away most of the IPR's of the software they produce to their customers. Thus, the lack of understanding legal aspects well in advance is now causing troubles for the company to reuse software code between and over different customer projects.

\section{Empirical analysis of marketing characteristics of the case companies}

We have analyzed the empirical data concerning each case supplier and their customer through finding both marketing competencies and problems in order to form a picture of the marketing challenges in the context of software component business (See Figure 2). The competencies and problems regarding the customer interface in the companies are especially evaluated through looking at both the relational challenges and market creation challenges.

One of the most important issues we found with respect to the two case companies in the product business end of the continuum ( $A$ and $B$ ) is the way product management is handled. Although there was pressure from the customer's side to tailor the component, the suppliers were not very willing to alter the component. It was possible to add new features to the component, but this was not made by the component seller, but the separate consultation or services business unit. The services were considered very costly and the supplier usually took the IPR's and thus sold the feature also to other customers, although one customer had paid for the development.

The Ada Technologies, the most close to the product business end of the continuum, was very concerned about developing traditional marketing activities. They put a lot of effort in developing their brand and advertising material, taking part in industry exhibitions etc. The company was rather young and existing customer relationships therefore also short. However, the company paid a lot of attention in analyzing the whole market; both the customers and potential competitors. Thus, their market knowledge formed an important marketing competence. 


\section{COMPONENT SUPPLIER BUSINESS LOGIC}

\section{MARKETING CHARACTERISTICS}

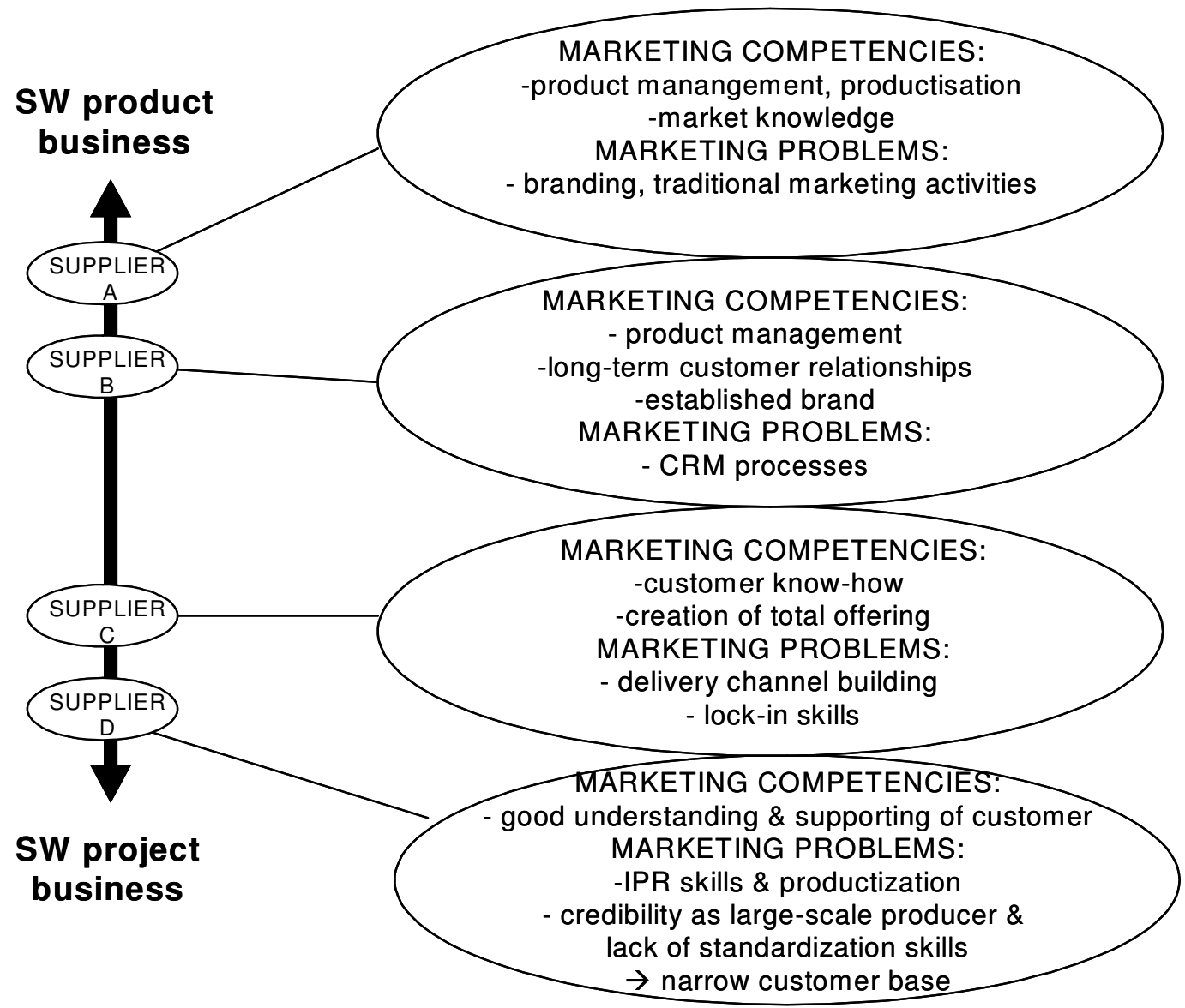

Fig. 2. Marketing characteristics of the case companies

The two case companies ( $C$ and $D$ ) in the project business end of the continuum were having not only similar kinds of competencies, but also similar kinds of problems related to marketing. Both of the suppliers had strong customer know-how, both in terms of customer need identification and in understanding customer's business processes. This know-how was acknowledged also by their customer, the Yosigemo. Cersa Automation had also rather developed competencies in creating a total offering for their customers, including highly tailored services but also more standardized product modules, i.e. components.

The marketing problems of these two project business oriented suppliers were related to the lack of productization skills. Cersa Automation already had more developed product and component business than the Dinera Technology had, but still even the Cersa Automation faced problems e.g. in building adequate delivery channels and creating successful logic for customer lock-in.

\section{A conceptual model for understanding the marketing challenges in the software component business}

Based on our theoretical review of the marketing challenges faced by component suppliers and on our empirical study we suggest that for overcoming the marketing challenges faced by the commercial software component suppliers, three issues should be considered: market creation, traditional marketing and relational competencies (See Figure 3). These can be traced back to the different logics of software companies. The relational competencies become evident from the project business, whereas the market creation and more traditional marketing competencies are more typical in the 
product business logic. Thus, although the software component business represents ideally highly productized business logic, we argue that also the relational competencies are necessary.

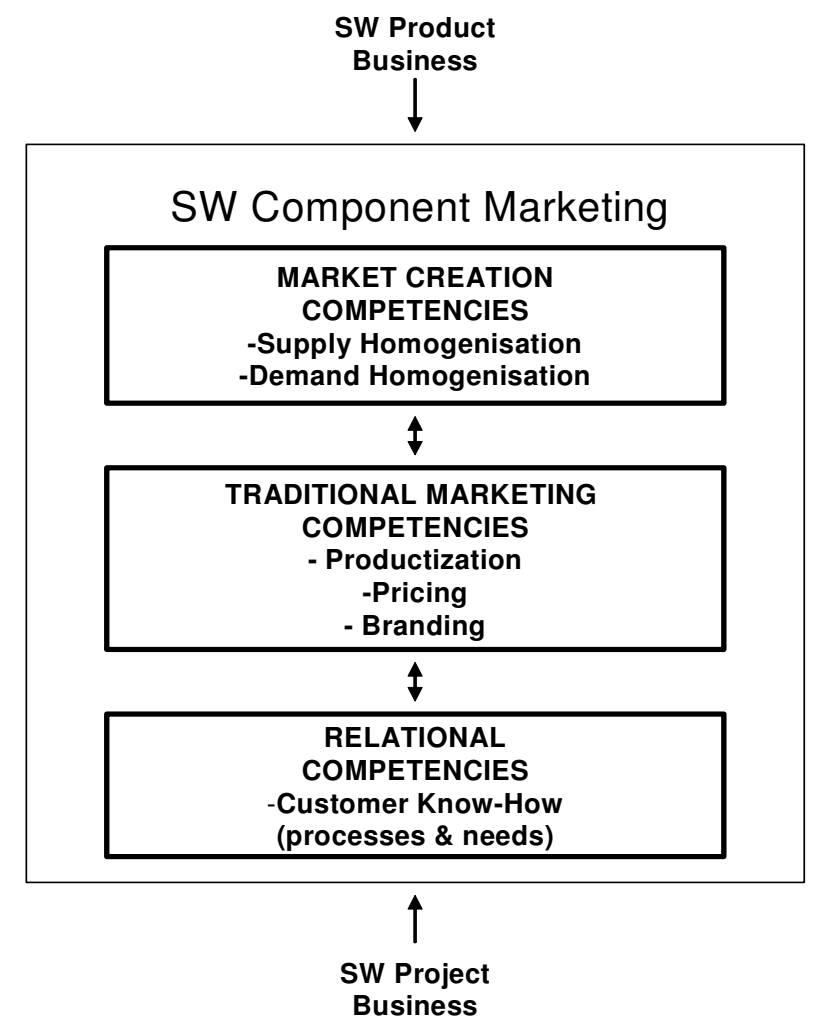

Fig. 3. A conceptual model for understanding the marketing challenges in the software component business.

From the perspective of software component supplier, knowing the customer needs thoroughly is very important. Relational competence refer to the competencies that suppliers need in knowing the customer needs and processes in order to develop the component and to release new versions of it along the component's life span. In project business, this competence is essential one, and easier to possess as the relationship between the supplier and the customer is closer and more co-operative. In more productized component business, however, this is difficult as the customer is not as close. Customers may consider the risks included into component high if the supplier remains very distant and resistant in taking in the customer needs. Thus, one of the tree elements that need attention is relational competence.

The second aspect we included into our model is the traditional marketing competence. By this we refer to the marketing activities such as branding and pricing. In the software component business, from the customer's perspective, the risks involved into the component are considered high. This is due to the fact that the component is usually included into larger software systems that are used in products and so on. Thus, the component reliability becomes very important as it may be very difficult to fix the problems in the component or change it later on. The component needs to operate well. One way of ensuring this, from the customer perspective, is to rely on established brands. To the component suppliers, this means that establishing a reliable brand needs a lot of attention. In addition to branding, also pricing needs to be carefully considered where the traditional marketing competencies are concerned. The software components are regarded as more cost efficient solutions, but the customers have difficulties in evaluating the total costs of buying and using components whereas the suppliers seem to have difficulties in determining the right pricing strategies (e.g. royalties or fixed price). The traditional marketing competencies crystallize into efficient productization. Product management is an essential part of the whole package. Questions concerning the standard versus extra cost features of the component need to be carefully considered and communicated to the customers. 
Finally, the market creation competencies direct the attention also in the whole market. Especially in the situation such as in the yet only emerging software component market, the importance of other actors in the market is high. It is not enough to concentrate on developing company's internal processes or management guidelines within single relationship. As the underlying idea in the software component business lies within competitive market, these should also be fostered by both buying and selling parties. Homogenization of both supply and demand needs to be advanced. From the supplier's perspective, it is important to consider the value that the component posses for the customer. On the one hand the market should be large enough, so that the prize of the component could be acceptable for the buyers. On the other hand the value of the component usually is higher as the level of the industry specificity of the component rises but this often degreases the size of the market. Thus, the optimal level of industry specificity of the component needs to be considered with respect of the homogenization of supply and demand in the market. This is, of course, where the standardization becomes an issue. Standardization enhances the interaction between the suppliers and the customers as standards can in best reduce the time-consuming integration phase where the component is integrated as part to the system. Therefore the active participation into the standardization development should be emphasized.

\section{Discussion}

Based on our empirical analysis that has taken into account both the component suppliers' and the customers' perspectives, we are able to present following conclusions and managerial implications.

Firstly, we want to emphasize that software component business does not fulfill at the moment the criteria of a genuine product business, although this kind of assumption is common in current literature concerning the software component markets. We would even like to question whether the ideal vision of pure transaction-based, faceless software component markets is even possible to achieve in as abstract, knowledge-intensive and dynamic industry as software industry is.

Secondly, based on our empirical analysis we argue that successful marketing and selling of software components does require competencies that are a mixture of typical product marketing competencies and typical project marketing competencies. For a company that has been operating in pure product business it is a challenge to achieve more customer know-how and to get closer to the customer. On the other hand, for a company that has its roots in the project business the biggest marketing challenges of software components is to learn how to productize the offering, e.g. how to price the component, how to build a brand and how to create adequate delivery channels. Thus, a software component supplier needs both the so called traditional marketing competencies and the more relational competencies. From a managerial point of view it is important to keep in mind this kind of complex mixture of product and project logic needed in succeeding in the software component business at the moment. It is not an easy task to change from product business logic towards project business logic and vice versa. As one solution we want to suggest that managers pay attention to the organization of the new business area. For example, when a software project company wants to start software component business it should create an own, rather independent business unit for the component business and to hire also such people to the unit that posses experience from product business.

Thirdly, we point out the need for market creation competencies in software component business. From a managerial point of view it is a big challenge to evaluate the total costs of developing software. When the software is developed in a project ordered by a customer, the development is usually charged based on the total hours that were spent on coding the needed software system. However, when a supplier is developing a software component, it usually does not have any paying customer before the component is ready, branded and successfully marketed. Thus, in this case the supplier is taking higher risks. One possible way to overcome this challenge is to find a co-operative customer that sees the component valuable enough to participate in the development costs of the component.

In all, the model developed in this study contributes to the current literature on software business especially by reviewing the problematic of emerging software component market from the supplier's point of view. As already stated, the software component marketing viewpoint has not yet been in foci of the current literature. We also want to suggest that the developed model has a wider contribution on the issue of customer relationship management in competitive markets beyond the context of software 
business. There are various kinds of relationships that are born also in highly competitive markets and these different kinds of relationships are better managed if we understand customer relationship management as an entity that takes into account not only the relational issues, but also the more traditional marketing issues.

This study has opened several future research avenues. We aim to further develop the empirical model presented in this study and also to test it in other contexts than just in the software component business. In addition, from a software business point of view one interesting area to further study is the open source software context, in which the marketing challenges and competencies most probably differ a lot from the traditional software business. For further development of the theoretical propositions made in this study, a comparing analysis of the occurrence of the different supplier capabilities identified by Möller and Törrönen (2003) and marketing competencies identified by Hooley, Greenley, Cadogan and Fahy (2005) in overcoming the marketing challenges in software project versus product business would be useful.

\section{References}

Alajoutsijärvi K,, Mannermaa K, and Tikkanen H. (1999), "Customer relationships and the small software firm. A framework for understanding challenges faced in marketing." Information \& Management 37 (3) 153-159

Anderson J.C. and Narus J.A. (1998), Business Market Management. Understanding, Creating, and Delivering Value. Prentice Hall, Upper Saddle River, New Jersey.

Bass, L., Clements, P. and Kazman, R. (1998), Software architecture in practice. Addison-Wesley, Reading, Massachusetts.

Brereton, P. and Budgen, D. (2000), "Component-Based Systems: A Classification of Issues". Computer 33 (11) 54-62.

Day, G. (1994) "The capabilities of market-driven organizations", Journal of Marketing 58 (4) 37-52.

Gibbert, M., Golfetto, F. and Zerbini, F. (2005), "What do we mean by "marketing" resources and competencies? A comment on Hooley, Greenley, Cadogan and Fahey (JBR 2005). Journal of Business Research, Article in Press, May 2005.

Harmon P. (1999) "The component market”. Component development strategies 9 (12) 1-16

Helander, N. (2004), Value-Creating Networks: An Analysis of the Software Component Business. Acta Universitatis Ouluensis, G Oeconimica 16, University of Oulu, Oulu.

Helander, N., Ulkuniemi P. and Seppänen, V. (2002), "Understanding Software Component Markets. The Value Creation Perspective." In: Software Quality - ECSQ 2002. Quality Connection - $7^{\text {th }}$ European conference on Software Quality, Helsinki, Finland, June 9-13, Proceedings Kontio J and Conradi R eds., Springer-Verlag Berlin Heidenberg, 256-266.

Hirvonen, P. and Helander, N. (2001), "Towards Joint Value Creation Processes in Professional Services" The TQM Magazine 13 (4): 281-291.

Hooley, G., Greenley, G., Cadogan, J. and Fahy, J. (2005), "The performance impact of marketing resources", Journal of Business Research 58 (1) 18-27.

IEEE Std 106, (1998), 1998 Edition. The Institute of Electrical and Electronics Engineers, Inc. United States of America

Liu, A. and Gorton I. (2003) "Accelerating COTS Middleware Acquisition: The i-Mate Process". IEEE Software 20 (2) 72-79. 
MacStravic, S. (1999), "The Value Marketing Chain in Health Care." Marketing Health Services 19 (Spring 99): 14-19.

Messerschmitt, D.G. and Szyperski, C. (2000), "Industrial and Economic Properties of Software: Technology, Processes, and Value" University of California at Berkeley Computer Science Division Technical Report UCB//CSD-01-1130, Jan. 18, 2001, and Microsoft Corporation Technical Report MSR-TR-2001-11, Jan. 18, 2001.

Meyers, B.C. and Oberndorf, P. (2001), Managing Software Acquisition. Open Systems and COTS Products. SEI Series in Software Engineering, Addison-Wesley.

Möller, K. and Törrönen, P. (2003) "Business suppliers' value creation potential", Industrial Marketing Management, 32 (2) 109-118.

Sprott, D. (2000), "Open Market Components”. A CBDi Forum Report, January 2000.

Szyperski, C. (1998), Component Software. Beyond Object-Oriented Programming. Addison Wesley Longman Ltd, New York.

Ulkuniemi P. and Seppänen V. (2004), "Management of COTS Software Component Acquisition in the Emerging Market”, IEEE Software, 21, (6), 76-82. 